\title{
Taking the first step: How to create a high-school linguistics course
}

\author{
L’Meese Greaney*
}

\begin{abstract}
While teachers might see the need for linguistics, the fear of not being "expert enough" can prevent high-school teachers from all disciplines from designing and teaching a linguistics course. Teachers, with or without subject matter expertise, who seek to establish a K-12 linguistics course need to work closely with administrators and stakeholders, maintain a "progress over perfection" mentality, consider the merits of exposing students to linguistics early instead of waiting for a national, standardized curriculum, and remain flexible in delivery.
\end{abstract}

Keywords. high-school linguistics; secondary linguistic education; K-12 linguistic curriculum design

1. Introduction. To create a class of any kind that inspires excitement in prospective high-school students is a difficult task, but to create a class that inspires excitement and centers on linguistics is a task few, thus far, have been willing to undertake. Tweens, teens, and young adults are everyday linguists, shaping language use, redefining, and creating meaning in new and old words. Despite being at the forefront of linguistic trends and research, most K-12 students in the United States do not have the opportunity or access to ground, share, or develop their fledgling linguistic expertise in a school-sanctioned linguistics course or with field experts. While some interest may exist in certain post-secondary academic circles to promote linguistics among K-12 learners, the beneficiaries of such efforts, the students, are largely unacquainted with the field and, therefore, cannot advocate for the creation and addition of linguistics courses in their course bulletins. To my knowledge, most efforts to design and implement K-12 linguistics courses are led by university professors in tandem with current K-12 teachers (as evident in discussions among members of several standing committees of the Linguistics Society of America, such as the Linguistics in the School Curriculum Committee and the Advanced Placement Linguistics Committee). Designing and implementing high-school linguistics course offerings requires a level of partnership and engagement between and among content experts, high-school administrators, parents, teachers, and students. Mapping out the steps to make linguistic curriculum accessible to high-school students in the United States reveals numerous obstacles including but not limited to:

- sourcing age- and skill-appropriate linguistic curriculum designers and design

- awareness of the field of linguistics and its academic, personal, and societal benefits among high-school students, parents, educators, and administrators

- Common Core guidelines for public-school curriculum development; National Collegiate Athletic Association (NCAA) guidelines for public and private curriculum development, and resultant lack of autonomy in curriculum design and implementation

- a dearth of teachers who are capable of and/or comfortable with teaching linguistics; lack of subject-area expertise

- high-school students' lack of familiarity with the study of linguistics; misconceptions that limit learners' understanding of linguistics to 'grammar'

\footnotetext{
*Author: L’Meese Greaney, Eastern Michigan University (lhgreaney@gmail.com).
} 
There is growing momentum surrounding the introduction of linguistics to K-12 students in the United States, as indicated by those creating a database of teachers in the United States offering K-12 linguistics courses, committees affiliated with the Linguistic Society of America, K-12 student-led linguistics clubs, and increasing high-school teacher attendance at the annual LSA meetings. The organized efforts to design and implement age-appropriate curriculum have been led largely by the Linguistic Society of America's Linguistics in the School Curriculum Committee (LiSC) and Advanced Placement (AP) Linguistics committee and their members. If a $\mathrm{K}-12$ teacher is not aware of these charges, is not a member of the LSA, or is unable to participate in a partnership with a university professor to design and implement a linguistic curriculum, the teacher must navigate the complexities of proposing, designing, and teaching a new course individually. This case study functions as an examination of one such pursuit by me, L'Meese Greaney, in the English Department of the Upper School (9-12) at Detroit Country Day School (DCDS) in Beverly Hills, Michigan.

In this paper, I detail the process of creating a student-centered curriculum that exposes students to, excites them about, and engages them in the study of linguistics. The goal is to help other high-school teachers gain the confidence and resources to teach linguistics. For any highschool teacher looking to introduce or reimagine a linguistics elective that is student-centered and is not reliant upon subject-mastery, I offer a process to pitch and framework for a highschool linguistics course. Thoroughly assessing all stakeholders' needs and drafting a course proposal with those needs in mind is a recommended first step. Empowered to deviate from a traditional classroom structure and order of introductory linguistic courses, a course was created shaped entirely by student interests.

2. Description of initiative. To develop a linguistics course without content expertise cannot and should not function as a hindrance to K-12 teachers who are interested in the subject matter and benefits of such a course. Rather, the challenge of a lack of expertise can be treated as any other consideration in the conceptualization phase of process development. From concept to implementation, I enumerated all potential obstacles and benefits of introducing a linguistics course as an English elective for 11th and 12th grade students. The obstacles, perceived or real, included marrying and fulfilling administrative goals, professional development goals, departmental guidelines, parents' goals, personal teaching-style and goals, and student interests while, simultaneously, overcoming my own fears surrounding my lack of subject-matter expertise. The considerations and concerns could not be ranked as no single consideration or concern took precedence over another; however, they were addressed in sequential order.

The first phase of the initiative centered on understanding and designing to the goals of the secondary stakeholders, administration, college counselors, and parents. The administration at DCDS had both content and conceptual requirements that new course proposals must fulfill. Identifying administrative goals was paramount in shaping the course, as the administrative team functioned as the final arbiter as to whether the course would run. My professional development goals, also an administrative necessity, were to amplify student voices, while combining joy and rigor with the goal of empowering students.

In addition, departmental and national-level curriculum guidelines were addressed. The curriculum guidelines of the school's English department and the National Collegiate Athletic Association were incorporated, as well as requirements from the high school's College Counseling department. Briefly, these requirements necessitated a minimum number of assignments and papers which had to align in comparability and quality with requirements of other English courses. 
The goals of the aforementioned were not as challenging to overcome as my fears surrounding a lack of subject matter expertise. I feared failing to do justice to the discipline and creating an engaging learning environment while maintaining my teaching style.

3. The classroom. My solution to a lack of subject matter expertise and existing curriculum paired with stakeholders' needs and my core teaching values led to the creation of a linguistics course that was student-led. The course was academically rigorous and designed to be personalized to an individual student's interests with the overarching goal of leaving students with the impression that linguistics is fun. Student feedback was positive, and the challenges students faced in adjusting to a flipped classroom were mitigated by year-end.

In this reimagined classroom, students chose the units, the order in which they were studied, and the articles that fueled their individual learning processes, thereby negating the need for the instructor to be the content expert. In a classroom of twenty students, each student researched and presented on a minimum of four linguistic topics with data from at least eight academic articles. Duplicate topics and articles between students were not permitted. Neither students nor I expected the instructor to read every source-document; the opportunity to become the contentexpert for their individual research papers and tasks empowered students and amplified their voices. Students were provided with necessary reading material to orient them to the nature of linguistics and the requisite subfields, maintaining accessibility and flexibility for the instructor. Classroom copies of linguistic textbooks and resources were available for loan, students were not required to purchase any texts for the course. If a singular textbook were assigned, the course may have been limited to the text and prevent the freedom students in my course felt to explore areas of interest.

Once students voted on what to study, I would source a multimedia introduction, be it a podcast or video, as well as other text-based resources to orient students to the subject. Using a multimedia source to introduce the topics kept students engaged and helped ensure accessibility for all learners, particularly those who might otherwise struggle with esoteric linguistic texts and/or those who specifically registered for the course due to learning differences that made reading and comprehension challenging. While most English classes were comprised of students on similar education tracts, my linguistics course was comprised of students who qualified to enroll in honors and AP electives as well as students who were recommended for a remedial English course: I requested permission from the English Department Chair and administration that all students who were interested be allowed to enroll. My vision for the course was such that students of all levels and abilities would have the opportunity to enjoy a bespoke learning experience exploring language. No student was deemed more or less capable in the pursuit of exploring their language and, as such, the materials needed to reflect the diverse set of abilities. With an eye toward accessibility, the unit centered on dialectal variation was introduced with Wired's (2021) YouTube video "Accent Expert Gives a Tour of U.S. Accents - Part One". Syntax was introduced with CrashCourse's (2020) "Syntax 1 - Morphosyntax: Crash Course Linguistics \#3". The purpose of introductory resources was not to deliver a thorough explanation of the linguistic subfield but to generate interest and provide a cursory overview to inspire students' individual research, through which process they would need to source additional videos and texts to develop their own understanding of the subfield. The resources and texts that students sourced while working on their individual research projects were aligned to and reflective of their academic and intellectual abilities.

To create an environment that was equitable to students of all backgrounds and abilities, I needed to challenge students' previously held notions of language, reinforced by prescriptive K- 
12 education. Level-setting to start the year was an important step in establishing that linguists focus on exploring and understanding language, not judging it. Despite their young age, by high school most of my students had formed strong opinions about the relative correctness of language. Students sought permission to use language in the classroom that represented how they would use language among their peers. Students perceived any deviation from prescriptive approaches to speaking and writing as 'rule breaking' and expressed concern of being judged or penalized in an academic setting. Creating a linguistic safe-space and fostering an appreciation of linguistic variations empowered students to be true to themselves, their interests, and abilities while, concurrently, fostering the notion that they were budding linguists, devoid of the perils of judgment. Students who were recommended for remedial courses and AP courses were able to work in small-group settings without concerns about how others would perceive them.

Removing the fear of linguistic judgment established a classroom culture of mutual respect that extended far beyond the use of language, enabling students to appreciate their diversity on numerous facets.

Students who were from disparate social groups and at opposite ends of the spectrum of academic abilities became collegial in class and friends outside of class. Students remarked on their new friendship, openly attributing them to a welcoming and non-competitive classroom environment centered on open-mindedness. The open-minded approach to linguistics transcended to an open-mindedness surrounding socio-economic status, race, and academic ability. The removal of linguistic judgment allowed and encouraged students to question other judgmental perceptions they have of their peers. By questioning the judgments, students challenged them. Multiple teachers and administrators remarked on how no classroom, to date, had been able to bridge the 'talent gap' in an academic setting. In sports, people of different academic abilities worked as a team, but in the classroom, they were divided. In linguistics, our classroom had a 'team' mentality. The AP-level students learned as much from the remedial students as they did from each other. The remedial students were able to observe and learn from their more academically accomplished peers without concern of comparison. In a traditional classroom where all students analyze shared texts, learning abilities and academic inclinations are more salient, serving as a point of comparison. In our classroom, students' research was rooted in their interests. As students were the content experts of their own presentations and papers, there was no room for comparison to one another. The course content became secondary to the shift in perspective and friendships formed among the students.

To reinforce the open-minded and curious approach toward language that linguists uphold, I started the school year with a folk linguistics map activity (Preston 1993). Students were provided with a blank map of the United States then asked to demarcate the country based on their perception of where regional dialects existed. Then, they were asked to generate two adjectives to describe the people within each linguistic border. Students' maps were aligned and compared as a class. After expressing surprise that their impressions of other regions and peoples of the United States overlapped significantly, students each conducted field research asking ten people outside of our classroom to complete a similar activity. With 200 maps completed, the resultant data showed trends among respondents' judgments about the socioeconomic status, intelligence, and respect due to citizens of the United States based on perceived dialectal borders. The exercise was illuminating for students because it demonstrated the ubiquity of judgment based on language, thus inspiring them to work, at least within the walls of our classroom, to dismantle prejudices and criticisms of their own and others' language use. Dually, the folk 
linguistics map activity served as an introduction to the scientific method, field research, and data analysis which were recurring themes in their reading and research throughout the year.

Exploring and dismantling linguistic prejudices was further supported with chapters one through three of Dialects at School: Educating Linguistically Diverse Students (Reaser et al. 2017). Although the Reaser text is geared toward educators, the students viewed themselves as ambassadors of linguistics among their larger peer groups and were easily able to digest the information and work through the embedded activities. Every unit featured the same framework in which I introduced an approachable video, such as Wolfram's Talking Black in America - The Story of African American English (2015) then followed up with a chapter from an approachable text, such as How English Works (Curzan \& Adams 2006) or Linguistics for Everyone (Denham \& Lobeck 2010) for definitions, examples, and more in-depth explanations, as needed. If approachable texts were not available, I provided one to two academic articles with my annotations, drawing attention to focus areas and fundamental concepts. Students would then read the common text(s) in groups of four, develop the annotations, complete a worksheet to clarify concepts and confirm understanding, then share out their findings to the larger group.

After a brief introduction to the unit, students identified a curiosity or question they wanted to explore further. Students were then asked to find one multimedia source and one academic text that could begin to answer their questions. If they could not find at least one academic text, they would adjust their question, either making the questions more broad or nuanced, depending on the availability of related research. If students struggled to develop a curiosity or question related to the over-arching subfield, they were directed to explore podcast episodes from Lingthusiasm (Gawne 2016-present) and Michigan Public Radio's That's What They Say podcast (Curzan \& Kruth 2013-present). Episodes from these podcasts were also assigned for required summer homework, a departmental requirement, between units, and for extra credit opportunities.

Once students solidified their research question and identified a multimedia source and an academic text, they worked to answer their questions. As needed, they would conduct field research or source additional academic articles. Students presented, critiqued, and revised their research over the course of four weeks. Following two, four-week cycles, students would take one week to develop one of their projects into a formal paper, in alignment with departmental guidelines. When building their research out into a formal paper, students were tasked with sourcing additional research and identifying potential weaknesses in their research or arguments. With intentionally limited instruction and gentle guidance, students learned how to research for personal pleasure, motivated by curiosity. In the process, they learned about the rich and diverse subfields and topics of study within linguistics: From the disappearing "rhotic r" of the Scottish accent to the oppression of immigrant voices in the workplace, students went on a journey of their new-found linguistic interests. Additional student-chosen topics included, but were not limited to, the influence of gender differences on discourse markers, slang used by professional basketball players, the generational evolution of the Appalachian dialect, as well as the analysis of Kurt Cobain's suicide letter and the Unabomber's manifesto. Students shared the hip-lingo in regularly scheduled "Slang Time" sessions, and the entirety of them competed in the North American Computational Linguistics Open (NACLO).

The course was fun to teach because it was not a traditional course. Being student-driven created a unique environment for me and the students. The primary challenge was finding resources that were age-appropriate and appropriate for all learners in the class with a relatively short turn-around time as student interests changed or evolved. If a particular unit was not 
productive due to a lack of resources or accessibility, we would truncate the unit, attempt to reach a common point of understanding, then move on to a new unit. If we finished a unit early, students had the option to lead miniature units. Both years the course ran, three partner-groups designed and taught mini units. If students were interested in forensic linguistics, for instance, they would identify an introductory resource, a chapter from a linguistic text or academic article, design a discussion and activity as well as two comprehension check quizzes or writing activities. The student-led miniature units enabled the students who were passionate about a subfield of linguistics to share their knowledge and expertise. The students who designed units also received a perfect-score for all assessments in that miniature unit. Students, whether or not they taught miniature units, were incredibly proud of the work they produced and embraced the process. Students regularly remarked that the linguistics course, more than any other course in their high-school career, challenged them to think independently, manage their time effectively, and prepared them for college. The classroom fostered independence and amplified student voices in a risk-free and supportive environment; if students needed assistance sourcing articles for their research or working through their research questions, they could ask for help without fear of judgment or failure.

4. Conclusion. Teachers considering the creation of a high-school linguistics course may share my challenges in appeasing stakeholders and overcoming a lack of subject matter expertise. They may also encounter challenges specific to their environment including adhering to school schedules, Common Core requirements, or professional development expectations. While the solutions will need to be customized, the framework of my course is flexible and can serve as a template for other teachers to adopt. The shortcomings of my approach depend largely on institutional requirements and the teacher's individual goals. In presenting a brief overview of the course design and approval process as well as the outcomes, other teachers may feel emboldened to reimagine what a linguistics course could look like in their respective schools.

Teachers seeking to establish a K-12 linguistics course that parallels mine would need to work closely with administrators and stakeholders, maintain a 'progress over perfection' mentality, consider the merits of exposing students to linguistics early instead of waiting for a national, standardized curriculum, and remain flexible in delivery. Thoroughly assessing all stakeholders' needs and drafting a course proposal with those needs in mind is a recommended first step. Attending the Linguistic Society of America conference to meet and learn from K-12 teachers and university professors who share the goals of exposing K-12 students to the study of linguistics would also be beneficial in culling resources, materials, and inspiration. The challenges outlined here and the intimidation of not being a content-expert, in teaching or linguistics, were mitigated by community support in and outside of my school. While most of the students who enrolled in my course may not take a linguistics course in college or become career linguists, a consistent piece of feedback from students was that the course made them more empathetic and less judgmental of others' experiences, which we understand largely through language. The ability to pursue their interests throughout the course retained students' interest and developed their confidence in the ability to be self-directed. Students consistently remarked that they felt more prepared for college knowing they could manage their time and navigate academic journals and databases. The first step in designing a linguistics course is to have confidence in your ability to create an environment where students are excited to explore their everyday language, and the rest will fall into place. 


\section{References}

CrashCourse. 2020, September 25. Syntax 1-Morphosyntax: Crash course linguistics \#3 [Video]. https://youtu.be/B1r1grQiLdk.

Curzan, Anne \& Michael Adams. 2006. How English works: A linguistic introduction. New York: Pearson/Longman.

Curzan, Anne \& Rebecca Kruth (Hosts). 2013-present. That's what they say [Audio podcast]. https://www.michiganradio.org/podcast/thats-what-they-say.

Denham, Kristin E., \& Anne C. Lobeck. 2010. Linguistics for everyone: An introduction. Boston, MA: Wadsworth/Cengage Learning.

Gawne, Claire (Producer). 2016-present. Lingthusiasm [Audio podcast]. https://lingthusiasm.com/episodes.

Hutcheson, Neal \& Danica Cullinan. (Directors). 2017. Talking Black in America - The story of African American English [Film]. The Language and Life Project.

Preston, Dennis R. 1993. Folk dialect maps. In A. Wayne Glowka \& Donald M. Lance (eds.), Language variation in North American English: Research and teaching. 105-118. New York: Modern Language Association of America.

Reaser, Jeffrey, Carolyn T. Adger, Walt Wolfram, \& Donna Christian. 2017. Dialects at school: Educating linguistically diverse students. New York: Routledge.

Wired. 2021, January 21. Accent expert gives a your of U.S. accents - Part One [Video]. https://youtu.be/H1KP4ztKK0A. 